\title{
Comparison of different approaches for modeling of heavy metal estimations
}

\author{
Parveen Sihag ${ }^{1} \cdot$ Ali Keshavarzi ${ }^{2}$. Vinod Kumar ${ }^{3}$ (I)
}

C Springer Nature Switzerland AG 2019

\begin{abstract}
Soil contamination by heavy metals is very important for environmental scientists due to the greater mobilization of metals and the possibility of contamination of groundwater. One of the most effective tools for evaluating the risk is the combination of experimentation with computer modeling. Modeling techniques are important in assessing the potential risks associated with heavy metals in the environment. Determination of models that can precisely evaluate the heavy metals in soils is an important need of agricultural researches, which could eradicate the weaknesses in the measurement of heavy metals in soils. The purpose of the present study is to test and compare different models according to their suitability for describing the estimation of heavy metals. The models used in this study were multilayer perceptron neural network (MLP), M5 model tree (M5) and bagging approach (BM5P). The data from 164 sampling sites from Neyshabur and Mashhad plains were taken in this study. The inputs combination according to feature selection-based correlation was used to feed the models. To model soil heavy metals, soil attributes, namely sand, silt, clay (as texture fractions), organic carbon, $\mathrm{pH}$ and available phosphorus, were entered in some models. To evaluate the performance of various techniques used in this study, several statistical indexes, including the correlation coefficient, root-mean-square error, Nash-Sutcliffe coefficient, Willmott's index $(d)$ and mean absolute error, were assessed. Comparison of different models for Fe, $\mathrm{Cu}, \mathrm{Mn}$ and $\mathrm{Zn}$ indicated that MLP is the most suitable method for estimations of Fe and Mn, whereas BM5P and M5P are the most suitable models for determinations of $\mathrm{Cu}$ and $\mathrm{Zn}$, respectively. This study concluded that machine learning models can be successfully applied to the rapid prediction of soil heavy metals using soil variables.
\end{abstract}

Keywords BM5P · Heavy metals · Khorasan-e-Razavi Province $\cdot$ MLP $\cdot$ M5P

\section{Abbreviations}

MLP Multilayer perceptron neural network

BM5P Bagging approach

OC Organic carbon

Ava.P Available phosphorus

CC Correlation coefficient

RMSE Root-mean-square error

NSE Nash-Sutcliffe coefficient

MAE Mean absolute error

Cu Copper

Zn Zinc

$\mathrm{Fe} \quad$ Iron $\begin{array}{ll}\text { Mn } & \text { Manganese } \\ \text { AAS } & \text { Atomic absorption spectrometer }\end{array}$

\section{Introduction}

Soil comprises reduced and non-renewable resources that required being preserved, although they are polluted by various heavy metals [1-6]. Heavy metals accumulation in soil have negative impact on the environment and endanger the human's health and ecosystems via energy and material cycling [7]. The industrial, urban and agricultural

$\bowtie$ Ali Keshavarzi, alikeshavarzi@ut.ac.ir; $\bowtie$ Vinod Kumar, vinodverma507@gmail.com | ${ }^{1}$ National Institute of Technology, Kurukshetra, Haryana, India. ${ }^{2}$ Laboratory of Remote Sensing and GIS, Department of Soil Science, University of Tehran, P.O. Box: 4111 , Karaj 31587-77871, Iran. ${ }^{3}$ Department of Botany, DAV University, Jalandhar, Punjab, India. 
activities are the major causes for soil contamination $[8,9]$. Reducing and controlling the pollution of heavy metals in soils is to find out the sources of contamination $[10,11]$. On local scale, agricultural soils are being polluted by addition of heavy metals through natural and human activities [12-14]. Heavy metals in agricultural soils are mainly derived from weathering of parent materials, industrial emissions, disposal of high metal wastes, fertilizers, agrochemicals, irrigation water, atmospheric accumulation and pesticides $[15,16]$. Each conclusion concerning the function of any assessment in soil quality and organization should be established on authentic data on the degree and causes of heavy metal contamination in a region [17]. Hence, the investigation and distribution of heavy metal pollution causes in agricultural soils on local level is important.

The elevated spatial diverseness of heavy metals in soils, the wide arrayness of pollution causes and improper long-term monitoring information are the issues for scientists to evaluate the multi-source pollution of heavy metals from agricultural soils on a local level; searching appropriate approaches to tackle this issue is important. For solving all these issues, modeling approaches serve as important techniques in investigation and apportionment of heavy metal source [18]. These techniques required a minute sample size, and consequently time and work are cost-efficient [19]. Diverse modeling approaches have been used for the determination of associations among spatial distribution of soil characteristics. Extrapolative mapping techniques such as geostatistical, linear and multiple regression, and neural networks have been effectively applied for soil mapping [20, 21]. In Iran, widespread usage of pesticides, fertilizers and fast expansion of industrial and urban development took place, but there is no appropriate data about agricultural soils of different land types in Iran and standard procedures regarding different modeling techniques. With this objective, the present research was made to develop models to determine its possibility to assess heavy metals such as $\mathrm{Fe}, \mathrm{Mn}, \mathrm{Cu}$ and $\mathrm{Zn}$ in agricultural soils of Northeastern Iran employing modeling.

\section{Materials and methods}

\subsection{Study area}

Neyshabur plain, Khorasan-e-Razavi Province, Northeast Iran, was chosen for the present study (Fig. 1). Neyshabur plain is situated between lat. $\left(35^{\circ} 40^{\prime} \mathrm{N}-36^{\circ} 40^{\prime} \mathrm{N}\right)$ and long. $\left(58^{\circ} 12^{\prime} \mathrm{E}-59^{\circ} 31^{\prime} \mathrm{E}\right)$ with altitude of $1256 \mathrm{~m}$ above mean sea level and Mashhad Plain is located between lat. $\left(35^{\circ} 59^{\prime} \mathrm{N}-37^{\circ} 04^{\prime} \mathrm{N}\right)$ and long. $\left(58^{\circ} 22^{\prime} \mathrm{E}-60^{\circ} 07^{\prime} \mathrm{E}\right)$, and 900-1500 $\mathrm{m}$ above sea level. The climate of Neyshabur plain is semiarid with average annual precipitation of $233.7 \mathrm{~mm}$ and average annual temperature of $14.5^{\circ} \mathrm{C}$. The irrigated farming is the major land use approach in Neyshabur plain. Mashhad plain is described by semiarid climate with average annual temperature and precipitation of $15.8^{\circ} \mathrm{C}$ and $222.1 \mathrm{~mm}$, respectively. The primary soil types are Calcaric Fluvisols, Calcaric Cambisols, Calcaric Regosols and Gypsic Regosols, found in colluvial fans, pediment plains, plateau and upper terraces, respectively. Mashhad plain is mainly consisting of granitic and metamorphic rocks. The major portions of these rocks are covered with loess deposit. Soil texture changed from loam to sandy loam, and sandy loam to sandy clay loam.

\subsection{Soil sampling and analysis}

A digital elevation model (DEM) with $10 \times 10 \mathrm{~m}$ grid size was prepared using ArcGIS software from topographic map (1:25,000 scale) with $10 \mathrm{~m}$ contour lines distance. A total of 164 soil samples were collected from 0 to $30 \mathrm{~cm}$ and 30 to $60 \mathrm{~cm}$ soil depth by stratified random sampling technique. The sampling points were prepared in such a way that indicate all the main soils and land use types. The collected soil samples were cleaned by removal of plant materials and other pebbles, air-dried, powered and sieved by using 2-mm sieve. The soil $\mathrm{pH}$ was determined with the help of digital $\mathrm{pH}$ meter [22]. Soil textural properties [sand $(0.05-2 \mathrm{~mm})$, silt $(0.002-0.05 \mathrm{~mm})$ and clay $(<0.002 \mathrm{~mm})$ ] were estimated by the hydrometer method [23]. Soil organic carbon (SOC) content was estimated by following Walkley and Black [24]. Heavy metals (Fe, Mn, $\mathrm{Cu}$ and $\mathrm{Zn}$ ) in the agricultural soils were estimated by atomic absorption spectrometer (AAS). The soil samples were digested by the aqua regia method by following the protocol of Kumar et al. [25]. The limits of detection of the instrument were: $\mathrm{Fe}(7.3 \mathrm{mg} / \mathrm{l}), \mathrm{Cu}(1.2 \mathrm{mg} / \mathrm{l}), \mathrm{Mn}(1.0 \mathrm{mg} / \mathrm{l})$ and $\mathrm{Zn}(1.6 \mathrm{mg} / \mathrm{l})$. For quality assurance and quality control (QA-AC), the standards and blanks were run after every five samples to check the $95 \%$ accuracy of instrument [1]. The $95-105 \%$ recovery rates for samples spiked with standards authenticated that the results were satisfactory [26].

\subsection{Multilayer perceptron neural network (MLP)}

McCulloch and Pitts [27] first time proposed the artificial neural network. In general, the layered perceptron neural network structure contains three layers: the input, hidden and target layers. Each layer includes the number of neurons (Fig. 2). The number of neurons in the input and output layers is determined by the nature of the problem under consideration, while the number of neurons in the hidden layers, as well as the number 
Fig. 1 Location of study area and sampling points (up: Mashhad plain, down: Neyshabur plain)

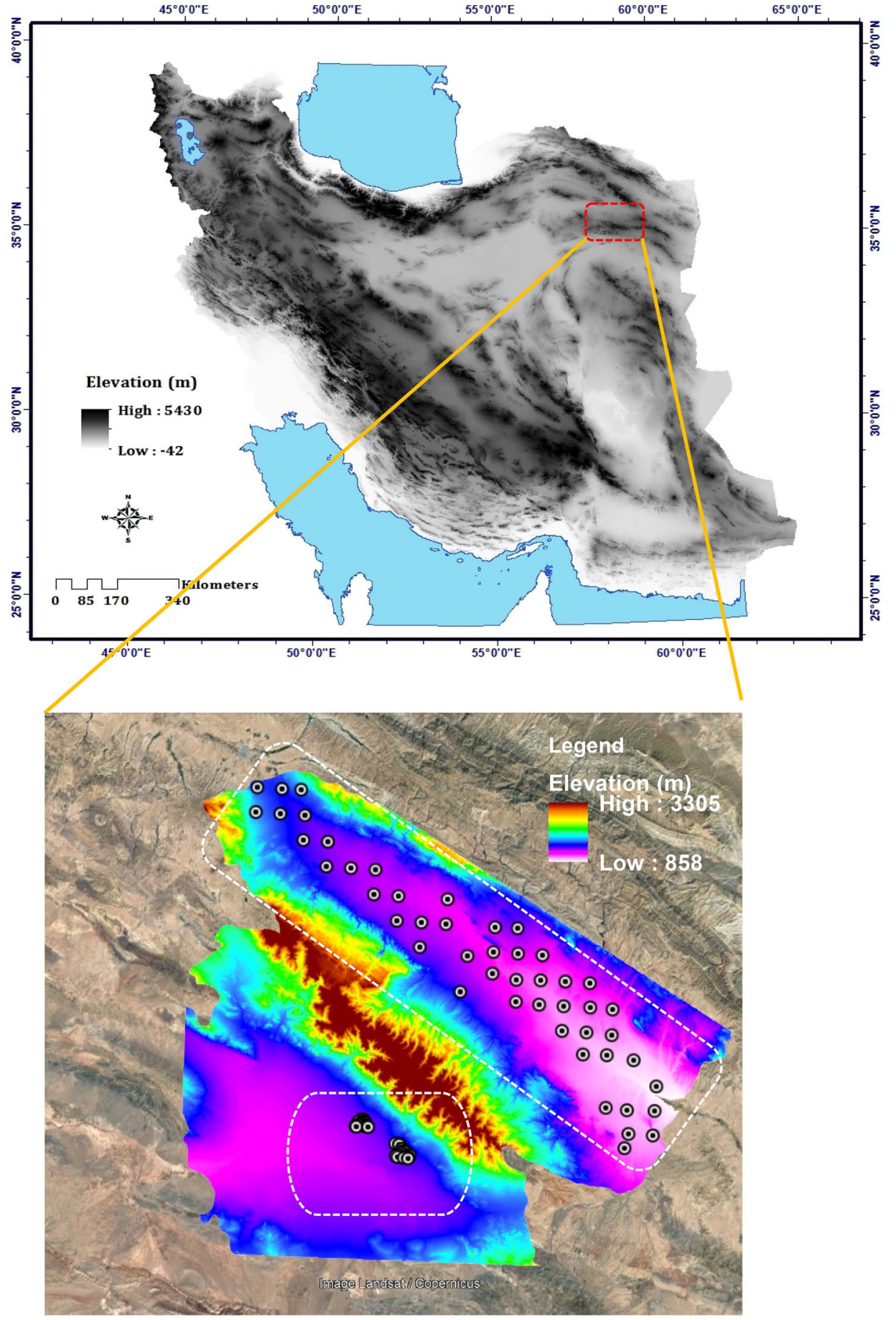

of these layers, is determined by the trial and errors to reduce the amount of error by the user $[28,29]$. Each of the neurons in the input layer is weighted whose value determines the effect of each variable on the input layer performance. Each neuron consists of two parts: In the first part, the weighted sum of the input values is computed, and in the second part, the output of the first part is in form of a mathematical function and through which the output of the neuron is calculated. This mathematical function is referred to as the actuator function, the threshold function, or the transfer function which functions like a nonlinear filter and makes the output of the neuron in a number range [30]. 
Fig. 2 Simple configuration of multilayer perceptron neural network

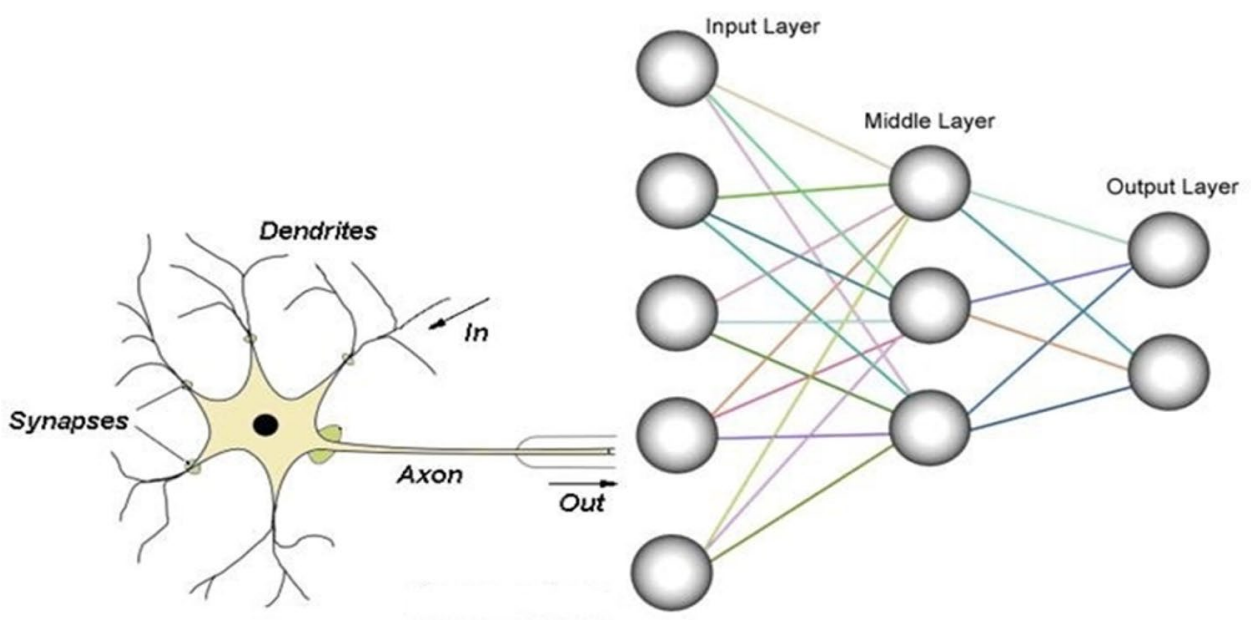

\subsection{M5 model tree (M5)}

M5 tree, introduced by Quinlan [31], is a decision tree learner for regression problems. This tree algorithm assigns linear regression functions at the terminal nodes and fits a multivariate linear regression model to each subspace by classifying or dividing the whole data space into several subspaces. The M5 tree method deals with continuous class problems instead of discrete classes and can handle tasks with very high dimensionality. It reveals piecewise information of each linear model constructed to approximate nonlinear relationships of the dataset.

The information about the splitting criteria for the M5 model tree is gained based on the calculation of error at each node. The error is analyzed by the standard deviation of the class values that arrive at a node. The attribute that maximizes the expected error reduction resulted from the testing of each attribute at that node is chosen for splitting at the node. The standard deviation reduction (SDR) is calculated by:

$\mathrm{SDR}=\operatorname{sd}(K)-\sum \frac{\left|K_{i}\right|}{|K|} \mathrm{sd}\left(K_{i}\right)$,

where $K$ indicates set of instances that attain the node; $K_{i}$ indicates the subset of illustrations that have the $i$ th product of the possible set; and sd indicates the standard deviation.

\subsection{Bagging approach (BM5P)}

Bagging is a machine learning ensemble meta-algorithm, which is designed to improve the stability and accuracy of machine learning algorithms used in statistical classification and regression. It also reduces variance and helps to avoid overfitting. Bagging is a special case of the model averaging approach. Bagging is a process to develop a training dataset by randomly drawing with substitute $X$ examples, where $X$ is the size of the initial training set [32], or a randomly selected part of the training set will be used for the construction of individual trees for every feature/feature blend. In case of bagging (bootstrap sample), training set consists about $70 \%$ of data from the initial dataset; thus, the remaining $30 \%$ of the data are missing from every tree matured. These missing data are called out-of-bag (out of the bootstrap sampling). Bagging leads to "improvements for unstable procedures" [33] which include, for example, ANN, classification and regression trees, and subset selection in multi-linear regression.

\subsection{Model evaluation criteria}

To evaluate the performance of various techniques used in this study, several statistical indexes, including the correlation coefficient (CC), root-mean-square error (RMSE), Nash-Sutcliffe coefficient (NSE), Willmott's index $(d)$ and mean absolute error (MAE), are assessed.

The closer the CC to unity, the higher the agreement among actual and predicted values. The precision in the prediction is higher when the values of RMSE and MAE approach zero. The closer the NSE and $d$ values to unity, the higher the accuracy in prediction. The considered performance evaluation parameters are defined as follows:

$\mathrm{CC}=\frac{a \sum k l-\left(\sum m\right)\left(\sum l\right)}{\sqrt{a\left(\sum k^{2}\right)-\left(\sum k\right)^{2}} \sqrt{n\left(\sum l^{2}\right)-\left(\sum l\right)^{2}}}$

$\mathrm{RMSE}=\sqrt{\frac{1}{a}\left(\sum_{i=1}^{a}(I-k)^{2}\right)}$ 


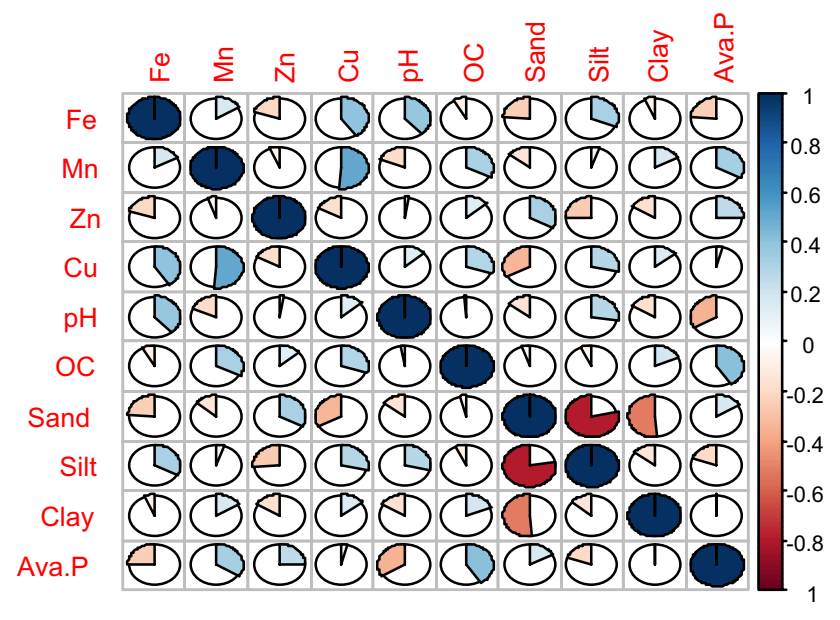

Fig. 3 Correlation on input and target variables

Table 1 Inputs combination according to feature selection-based correlation $(n=164)$

\begin{tabular}{ll}
\hline Target & Input \\
\hline Fe $(\mathrm{mg} / \mathrm{kg})$ & Sand + silt + pH + Ava.P \\
$\mathrm{Mn}(\mathrm{mg} / \mathrm{kg})$ & $\mathrm{OC}+\mathrm{clay}+\mathrm{pH}+$ Ava.P \\
$\mathrm{Zn}(\mathrm{mg} / \mathrm{kg})$ & Sand + silt + clay + Ava.P \\
$\mathrm{Cu}(\mathrm{mg} / \mathrm{kg})$ & Sand + silt + OC \\
\hline
\end{tabular}

$d=1-\frac{\sum_{i=1}^{a}(I-k)^{2}}{\sum_{i=1}^{a}(|I-\bar{k}|)+(|k-\bar{k}|)^{2}}$

$\mathrm{NSE}=1-\frac{\sum_{i=1}^{a}(l-k)^{2}}{\sum_{i=1}^{a}(k-\bar{k})^{2}}$

$\mathrm{MAE}=\frac{1}{a}\left(\sum_{i=1}^{a}|I-k|\right)$,

where $k$ are the observed values, / predicted values and $a$ number of observations.

\subsection{Model development}

Total dataset consists of 164 observations of $\mathrm{Fe}, \mathrm{Mn}, \mathrm{Zn}$, $\mathrm{Cu}, \mathrm{pH}, \mathrm{OC}$, sand, silt, clay and available P (Ava. P). Out of 164 observations, 117 were selected for model preparation, 24 were selected for testing and rest 23 were used for validation purposes. Figure 3 indicates the correlation among various variables, and input combination for model development for $\mathrm{Fe}, \mathrm{Mn}, \mathrm{Zn}$ and $\mathrm{Cu}$ is given in Table 1.

\subsection{Implementation of machine learning methods}

Five standard statistical measures, CC, RMSE, $d$, NSE and $M A E$, were selected to assess the performance of the machine learning methods. Numerous trials were carried out to find optimum value of primary parameters. Higher values of CC, $d$ and NSE and lesser values of RMSE and MAE indicate better estimation accuracy of the models. In M5P, calibration of models was done by changing the value of number of instances allowed at each node $(m)$, and iteration and number of instances are the primary parameters of Bagged M5P tree model. Hidden layers, number of neurons, learning rate, momentum and iteration are the primary parameters for the ANN model.

\section{Results}

\subsection{Models for Fe $(\mathrm{mg} / \mathrm{kg})$}

\subsubsection{Dataset}

The preparation of training, testing and validation dataset is like $\mathrm{Zn}, \mathrm{Cu}$ and $\mathrm{Mn}$ dataset. Descriptive statistics of total dataset for $\mathrm{Fe}(\mathrm{mg} / \mathrm{kg})$ are represented in Table 2, in which $\mathrm{pH}$, sand, silt and Ava. $\mathrm{P}$ are input parameters and $\mathrm{Fe}$ is the output. Descriptive statistics of datasets utilized for training ( $n=117)$, testing ( $n=24)$ and validation $(n=23)$ for $\mathrm{Fe}(\mathrm{mg} / \mathrm{kg})$ are listed in Table 3. Figure 4 indicates the 3D surface plot of Fe $(\mathrm{mg} / \mathrm{kg})$ against silt (\%) and $\mathrm{pH}$.

\subsubsection{Assessment of model's performance in $\mathrm{Fe}(\mathrm{mg} / \mathrm{kg})$ estimation in soil}

Performance evaluation parameters considered for model's performance evaluation are same as for implementing $\mathrm{Zn}, \mathrm{Cu}$ and $\mathrm{Mn}$ models' evaluation. Figure 5 shows the scatter plot between actual and predicted $\mathrm{Fe}(\mathrm{mg} / \mathrm{kg})$ in soil using MLP-, M5P- and Bagged M5P-based models for training, testing and validation stages. The prediction accuracy of $M L P$ model $(R M S E=1.4625, M A E=1.0473$ for testing and $\mathrm{RMSE}=1.2890, \mathrm{MAE}=0.9890$ for validation $)$ is found higher than M5P and BM5P models. Table 4 indicates that MLP model is most suitable model than M5P-and BM5P-based models for the estimation of Fe for this dataset. 
Table 2 Descriptive statistics for $\mathrm{Fe}, \mathrm{Cu}, \mathrm{Mn}$ and $\mathrm{Zn}(\mathrm{mg} / \mathrm{kg})$ $(n=164)$
Table 3 Descriptive statistics of datasets utilized for training, testing and validation

\begin{tabular}{lccccccr}
\hline Variables & Mean & Min & Max & SD & CV & Skewness & Kurtosis \\
\hline Fe & 3.56 & 1.16 & 9.64 & 1.61 & 45.4 & 1.01 & 1.07 \\
pH & 8.01 & 7.5 & 8.40 & 0.18 & 2.29 & -0.62 & 0.02 \\
Sand & 35.74 & 13.0 & 73.0 & 11.03 & 30.86 & 0.70 & 0.92 \\
Ava.P & 12.68 & 1.20 & 63.2 & 12.9 & 102.1 & 1.90 & 3.26 \\
Silt & 43.66 & 19.0 & 66.0 & 9.55 & 21.88 & -0.09 & -0.49 \\
Cu (mg/kg) $(n=164)$ & & & & & & \\
Cu & 1.31 & 0.62 & 3.46 & 0.48 & 36.5 & 1.19 & 2.11 \\
OC & 0.58 & 0.11 & 1.61 & 0.31 & 53.4 & 1.36 & 2.04 \\
Sand & 35.74 & 13.0 & 73.0 & 11.03 & 30.8 & 0.70 & 0.92 \\
Silt & 43.66 & 19.0 & 66.0 & 9.55 & 21.8 & -0.09 & -0.49 \\
Mn (mg/kg) $(n=164)$ & & & & & & \\
Mn & 6.80 & 1.64 & 21.0 & 3.29 & 48.4 & 1.51 & 3.23 \\
pH & 8.01 & 7.50 & 8.40 & 0.18 & 2.2 & -0.62 & 0.02 \\
OC & 0.58 & 0.11 & 1.61 & 0.31 & 53.4 & 1.36 & 2.04 \\
Clay & 20.59 & 4.00 & 41.0 & 6.95 & 33.7 & 0.12 & -0.29 \\
Ava.P & 12.68 & 1.20 & 63.2 & 12.9 & 102.1 & 1.90 & 3.26 \\
Zn (mg/kg) $(n=164)$ & & & & & & \\
Zn & 1.63 & 0.20 & 13.9 & 2.68 & 163.9 & 3.04 & 8.88 \\
Sand & 35.74 & 13.0 & 73.0 & 11.03 & 30.8 & 0.70 & 0.92 \\
Silt & 43.66 & 19.0 & 66.0 & 9.55 & 21.8 & -0.09 & -0.49 \\
Clay & 20.59 & 4.0 & 41.0 & 6.95 & 33.7 & 0.12 & -0.29 \\
Ava.P & 12.68 & 1.2 & 63.2 & 12.95 & 102.1 & 1.9 & 3.26 \\
\hline
\end{tabular}

The data were significant at $P<0.05$

\begin{tabular}{llllllll}
\hline & Mean & Minimum & Maximum & SD & C.V. & Skewness & Kurtosis \\
\hline Fe $(\mathrm{mg} / \mathrm{kg})$ & & & & & & & \\
Train $(n=117)$ & 3.53 & 1.16 & 9.64 & 1.50 & 42.5 & 0.99 & 1.67 \\
Test $(n=24)$ & 3.75 & 1.38 & 8.76 & 2.03 & 54.2 & 0.99 & 0.15 \\
Validation $(n=23)$ & 3.51 & 1.38 & 7.72 & 1.75 & 50.1 & 0.99 & 0.22 \\
Cu $(\mathrm{mg} / \mathrm{kg})$ & & & & & & & \\
Train $(n=117)$ & 1.33 & 0.62 & 3.46 & 0.49 & 37.2 & 1.41 & 2.80 \\
Test $(n=24)$ & 1.30 & 0.66 & 2.16 & 0.49 & 37.8 & 0.40 & -1.26 \\
Validation $(n=23)$ & 1.25 & 0.68 & 2.16 & 0.40 & 32.0 & 0.36 & -0.64 \\
Mn $(\mathrm{mg} / \mathrm{kg})$ & & & & & & & \\
Train $(n=117)$ & 6.64 & 1.64 & 21.06 & 3.04 & 45.8 & 1.63 & 4.46 \\
Test $(n=24)$ & 6.63 & 2.02 & 18.08 & 3.65 & 55.1 & 1.59 & 3.14 \\
Validation $(n=23)$ & 7.80 & 2.16 & 18.2 & 4.04 & 51.8 & 1.02 & 1.22 \\
Zn $(\mathrm{mg} / \mathrm{kg})$ & & & & & & & \\
Train $(n=117)$ & 1.71 & 0.2 & 13.9 & 2.78 & 162.3 & 3.07 & 9.12 \\
Test $(n=24)$ & 1.28 & 0.2 & 10.1 & 2.36 & 184.2 & 3.26 & 10.14 \\
Validation $(n=23)$ & 1.59 & 0.3 & 10.46 & 2.52 & 158.3 & 2.82 & 7.70 \\
\hline
\end{tabular}

The data were significant at $P<0.05$

\subsection{Models for $\mathrm{Cu}(\mathrm{mg} / \mathrm{kg})$}

\subsubsection{Dataset}

The preparation of training, testing and validation dataset is like $\mathrm{Zn}$ dataset. Descriptive statistics of total dataset for
$\mathrm{Cu}(\mathrm{mg} / \mathrm{kg})(n=164)$ are represented in Table 2 , in which organic carbon $(O C)$, sand and silt are input parameters and $\mathrm{Cu}$ is the output. Descriptive statistics of datasets utilized for training ( $n=117)$, testing $(n=24)$ and validation $(n=23)$ for $\mathrm{Cu}(\mathrm{mg} / \mathrm{kg})$ are listed in Table 3. Figure 6 


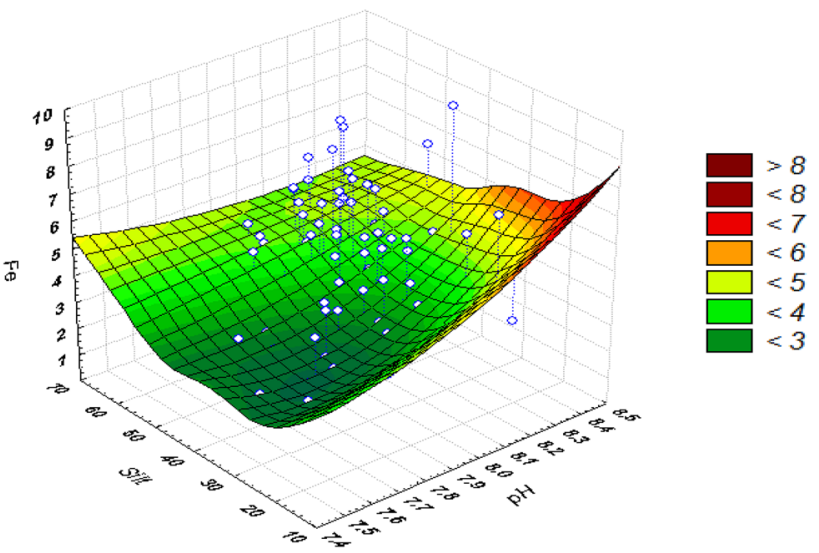

Fig. 4 3D surface plot of $\mathrm{Fe}(\mathrm{mg} / \mathrm{kg})$ against $\mathrm{pH}$ and silt (\%)
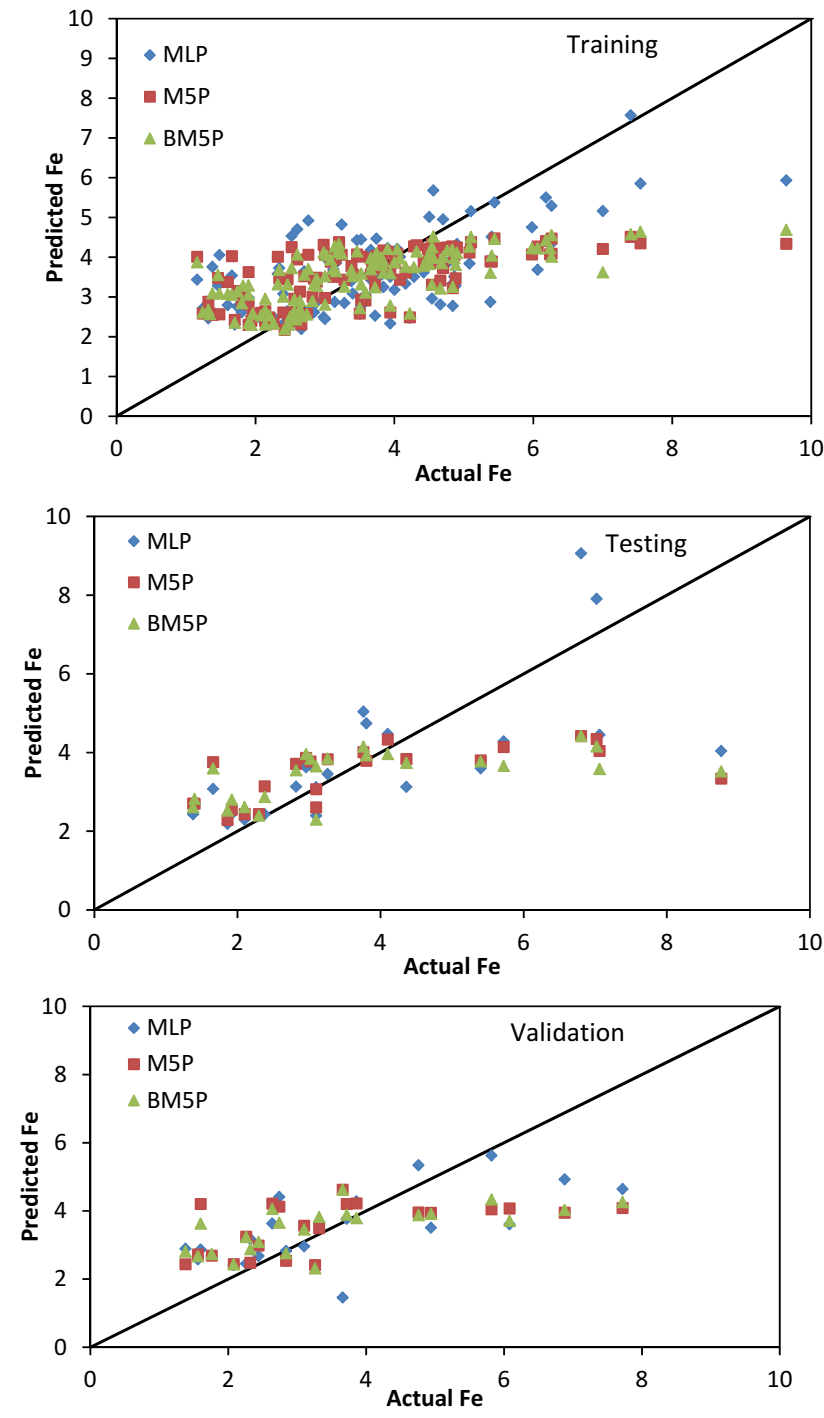

Fig. 5 Performance of MLP, M5P and BM5P for estimating Fe

Table 4 Performance evaluation parameters for MLP, M5P and BM5P techniques using $\mathrm{Fe}, \mathrm{Cu}, \mathrm{Mn}, \mathrm{Zn}$ dataset

\begin{tabular}{|c|c|c|c|c|c|}
\hline Approaches & CC & RMSE & NSE & $d$ & MAE \\
\hline \multicolumn{6}{|l|}{ Fe dataset } \\
\hline \multicolumn{6}{|c|}{ Training dataset } \\
\hline MLP & 0.665 & 1.119 & 0.442 & 0.778 & 0.863 \\
\hline M5P & 0.625 & 1.197 & 0.361 & 0.663 & 0.885 \\
\hline BM5P & 0.685 & 1.153 & 0.407 & 0.683 & 0.850 \\
\hline \multicolumn{6}{|c|}{ Testing dataset } \\
\hline MLP & 0.693 & 1.462 & 0.461 & 0.812 & 1.047 \\
\hline M5P & 0.615 & 1.691 & 0.280 & 0.562 & 1.181 \\
\hline BM5P & 0.569 & 1.748 & 0.231 & 0.508 & 1.278 \\
\hline \multicolumn{6}{|c|}{ Validation dataset } \\
\hline$M L P$ & 0.668 & 1.289 & 0.438 & 0.747 & 0.989 \\
\hline M5P & 0.543 & 1.458 & 0.281 & 0.597 & 1.153 \\
\hline BM5P & 0.643 & 1.398 & 0.339 & 0.603 & 1.111 \\
\hline \multicolumn{6}{|l|}{ Cu dataset } \\
\hline \multicolumn{6}{|c|}{ Training dataset } \\
\hline MLP & 0.451 & 0.440 & 0.203 & 0.572 & 0.331 \\
\hline M5P & 0.573 & 0.409 & 0.312 & 0.636 & 0.311 \\
\hline BM5P & 0.603 & 0.403 & 0.330 & 0.633 & 0.306 \\
\hline \multicolumn{6}{|c|}{ Testing dataset } \\
\hline MLP & 0.689 & 0.359 & 0.450 & 0.747 & 0.324 \\
\hline M5P & 0.599 & 0.395 & 0.332 & 0.650 & 0.356 \\
\hline BM5P & 0.673 & 0.379 & 0.386 & 0.672 & 0.349 \\
\hline \multicolumn{6}{|c|}{ Validation dataset } \\
\hline MLP & 0.632 & 0.316 & 0.357 & 0.707 & 0.271 \\
\hline M5P & 0.614 & 0.325 & 0.317 & 0.675 & 0.287 \\
\hline BM5P & 0.678 & 0.306 & 0.398 & 0.692 & 0.253 \\
\hline \multicolumn{6}{|l|}{ Mn dataset } \\
\hline \multicolumn{6}{|c|}{ Training dataset } \\
\hline MLP & 0.501 & 2.623 & 0.251 & 0.619 & 1.968 \\
\hline M5P & 0.622 & 2.453 & 0.345 & 0.649 & 1.841 \\
\hline BM5P & 0.627 & 2.424 & 0.360 & 0.666 & 1.806 \\
\hline \multicolumn{6}{|c|}{ Testing dataset } \\
\hline MLP & 0.698 & 2.744 & 0.412 & 0.695 & 2.079 \\
\hline M5P & 0.554 & 3.067 & 0.266 & 0.579 & 2.429 \\
\hline BM5P & 0.258 & 3.710 & -0.073 & 0.476 & 2.891 \\
\hline \multicolumn{6}{|c|}{ Validation dataset } \\
\hline$M L P$ & 0.343 & 3.936 & 0.010 & 0.507 & 2.934 \\
\hline M5P & 0.047 & 4.242 & -0.148 & 0.355 & 3.006 \\
\hline BM5P & 0.153 & 4.131 & -0.089 & 0.388 & 2.958 \\
\hline \multicolumn{6}{|l|}{ Zn dataset } \\
\hline \multicolumn{6}{|c|}{ Training dataset } \\
\hline MLP & 0.607 & 2.202 & 0.367 & 0.708 & 1.289 \\
\hline M5P & 0.605 & 2.278 & 0.323 & 0.614 & 1.339 \\
\hline BM5P & 0.590 & 2.289 & 0.316 & 0.614 & 1.345 \\
\hline \multicolumn{6}{|c|}{ Testing dataset } \\
\hline MLP & 0.960 & 0.828 & 0.871 & 0.967 & 0.710 \\
\hline M5P & 0.773 & 1.751 & 0.426 & 0.699 & 1.246 \\
\hline BM5P & 0.785 & 1.697 & 0.461 & 0.733 & 1.223 \\
\hline \multicolumn{6}{|c|}{ Validation dataset } \\
\hline MLP & 0.338 & 2.361 & 0.088 & 0.297 & 1.391 \\
\hline M5P & 0.552 & 2.115 & 0.268 & 0.535 & 1.188 \\
\hline BM5P & 0.487 & 2.214 & 0.199 & 0.445 & 1.372 \\
\hline
\end{tabular}


Table 4 (continued)

Coefficient of correlation (CC), root-mean-square error (RMSE), Nash-Sutcliffe coefficient (NSE), Willmott's index (d) and mean absolute error (MAE)

Bold italic values are indicated to the best suited model for the estimation of particular heavy metal

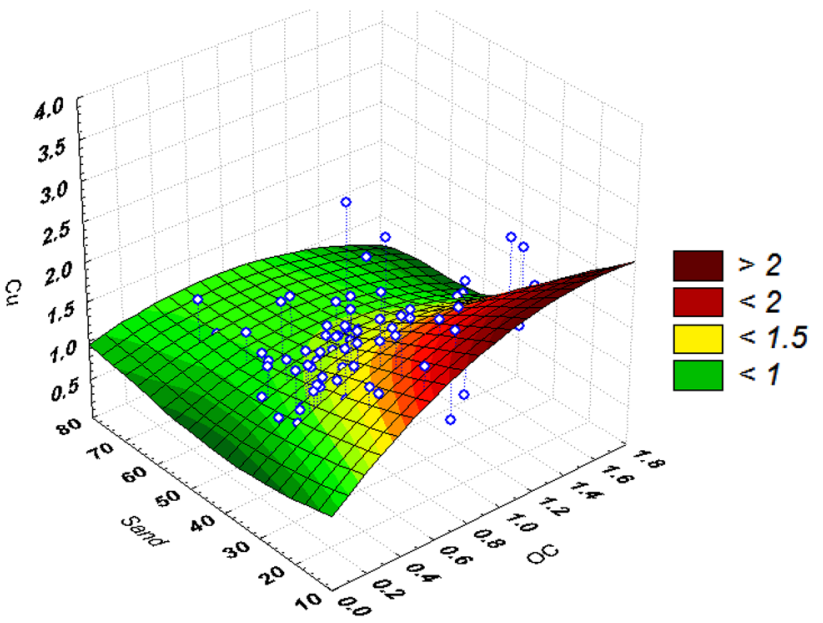

Fig. 6 3D surface plot of $\mathrm{Cu}(\mathrm{mg} / \mathrm{kg})$ against OC (\%) and sand (\%)

indicates the 3D surface plot of $\mathrm{Cu}(\mathrm{mg} / \mathrm{kg})$ against $\mathrm{OC}$ (\%) and sand (\%).

\subsubsection{Assessment of model's performance in $\mathrm{Cu}(\mathrm{mg} / \mathrm{kg})$ estimation in soil}

Performance evaluation parameters considered for model's performance evaluation are same as for implementing Fe model evaluation. Figure 7 shows the scatter plot between actual and predicted $\mathrm{Cu}(\mathrm{mg} / \mathrm{kg})$ in soil using MLP-, M5P- and Bagged M5P-based models for training, testing and validation stages. The prediction accuracy of $\mathrm{BM} 5 \mathrm{P}$ model $(\mathrm{RMSE}=0.3794, \mathrm{MAE}=0.3498$ for testing and $R M S E=0.3060, M A E=0.2537$ for validation) is found higher than MLP- and M5P-based models.

\subsection{Models for Mn $(\mathrm{mg} / \mathrm{kg})$}

\subsubsection{Dataset}

The preparation of training, testing and validation dataset is like Fe and Cu dataset. Descriptive statistics of total dataset for $\mathrm{Mn}(\mathrm{mg} / \mathrm{kg})(n=164)$ are represented in Table 2, respectively, in which $\mathrm{pH}$, organic carbon (OC), clay and Ava. $P$ are input parameters and $M n$ is the output. Descriptive statistics of datasets utilized for training $(n=117)$, testing $(n=24)$ and validation $(n=23)$ for $\mathrm{Mn}(\mathrm{mg} / \mathrm{kg})$ are listed
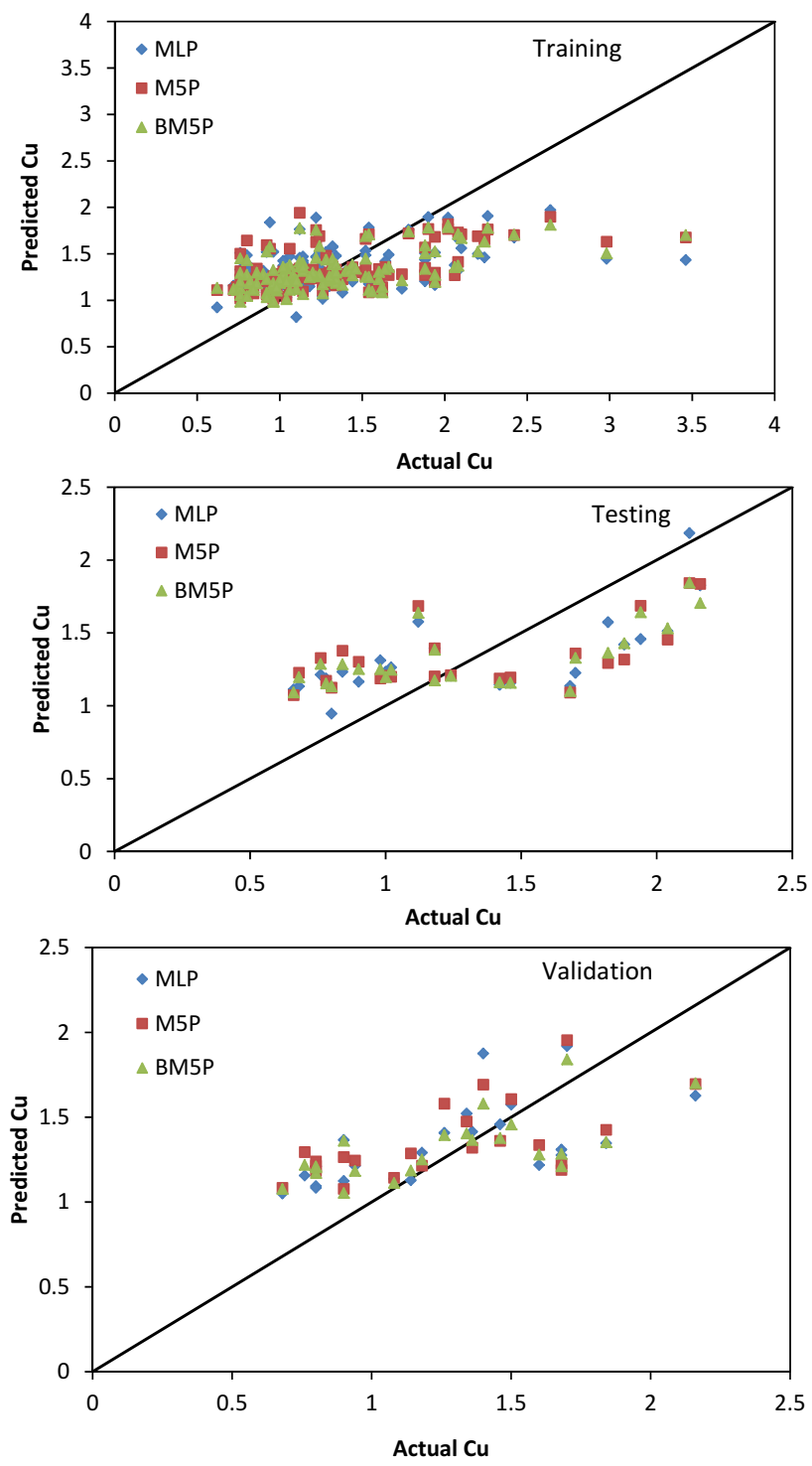

Fig. 7 Performance of MLP, M5P and BM5P for estimating Cu

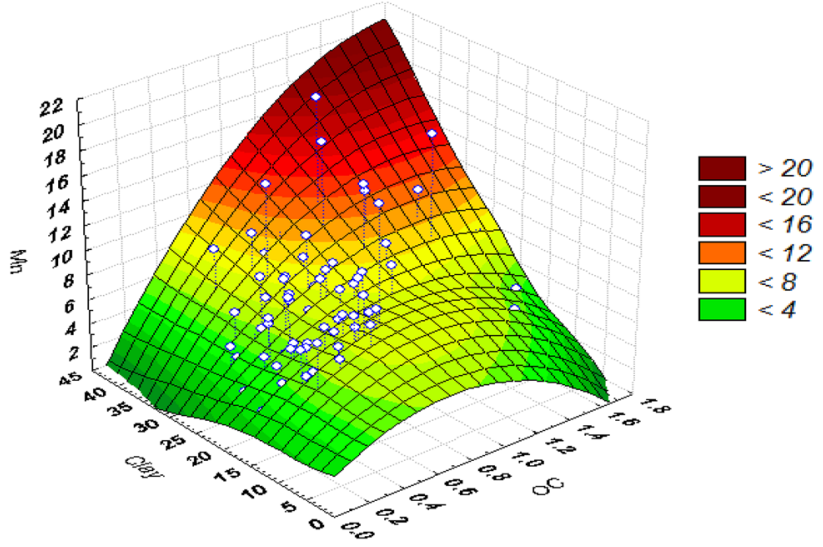

Fig. 8 3D surface plot of $\mathrm{Mn}(\mathrm{mg} / \mathrm{kg})$ against OC (\%) and clay (\%)

\section{SN Applied Sciences}


in Table 3. Figure 8 indicates the 3D surface plot of $M n$ $(\mathrm{mg} / \mathrm{kg})$ against clay (\%) and OC (\%).

\subsubsection{Assessment of model's performance in $\mathrm{Mn}(\mathrm{mg} / \mathrm{kg})$ estimation in soil}

Performance evaluation parameters considered for model's performance evaluation are same as for implementing Fe and Cu models' evaluation. Figure 9 shows the scatter plot between actual and predicted $\mathrm{Mn}(\mathrm{mg} / \mathrm{kg})$ in soil using MLP-, M5P- and Bagged M5P-based models for training, testing and validation stages. The prediction accuracy of $M L P$ model $(\mathrm{RMSE}=2.7447, \mathrm{MAE}=2.0795$ for testing and $\mathrm{RMSE}=3.9365, \mathrm{MAE}=2.9342$ for validation) is found higher than M5P and BM5P models. Table 4 indicates that MLP model is most suitable model than M5P-and BM5P-based models for the estimation of $\mathrm{Mn}$ in soil for this dataset.
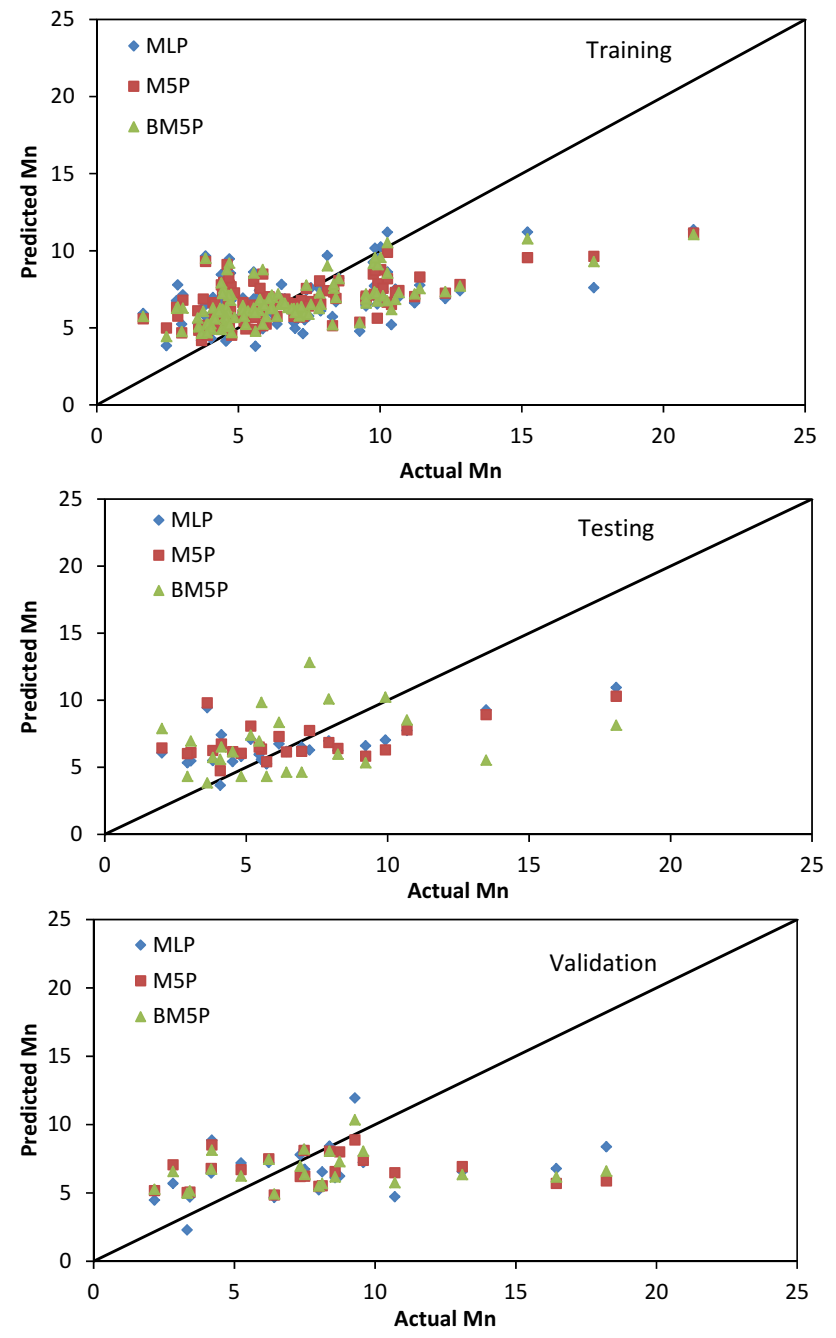

Fig. 9 Performance of MLP, M5P and BM5P for estimating Mn

\subsection{Models for $\mathrm{Zn}(\mathrm{mg} / \mathrm{kg})$}

\subsubsection{Dataset}

The whole dataset containing 164 observations from field was divided into three parts such as training, testing and validation, respectively. Training data involve $70 \%$ of the total data chosen randomly from whole dataset, while testing and validation data involve remaining $15 \%$ and $15 \%$ of the total dataset. Descriptive statistics of total dataset for $\mathrm{Zn}(\mathrm{mg} / \mathrm{kg})(n=164)$ are given in Table 2, and descriptive statistics of datasets utilized for training $(n=117)$, testing $(n=24)$ and validation $(n=23)$ for $\mathrm{Zn}(\mathrm{mg} / \mathrm{kg})$ are represented in Table 3 in which sand, clay, silt and Ava. $P$ are input parameters and $\mathrm{Zn}$ is the target. Figure 10 indicates the $3 D$ surface plot of $Z n(m g / k g)$ against sand (\%) and silt (\%).

\subsubsection{Assessment of model's performance in $\mathrm{Zn}(\mathrm{mg} / \mathrm{kg})$ estimation in soil}

To compare the performance of models, CC, RMSE, NSE, $d$ and MAE values were considered as performance evaluation parameters. Figure 11 illustrates the scatter plot between actual and predicted $\mathrm{Zn}(\mathrm{mg} / \mathrm{kg})$ in soil using MLP-, M5P- and Bagged M5P-based models for training, testing and validation stages. Few predicted values of $Z n$ by MLP are negative. MLP model is not suitable for the estimation of $\mathrm{Zn}$ in soil. The prediction accuracy of M5P model $(\mathrm{RMSE}=1.7513, \mathrm{MAE}=1.2464$ for testing and $\mathrm{RMSE}=2.1154, \mathrm{MAE}=1.1885$ for validation) is found higher than BM5P model (RMSE $=1.6979, \mathrm{MAE}=1.2230$ for testing and $\mathrm{RMSE}=2.2140, \mathrm{MAE}=1.3727$ for validation). Table 4 indicates that M5P model is most suitable model than MLP and BM5P.

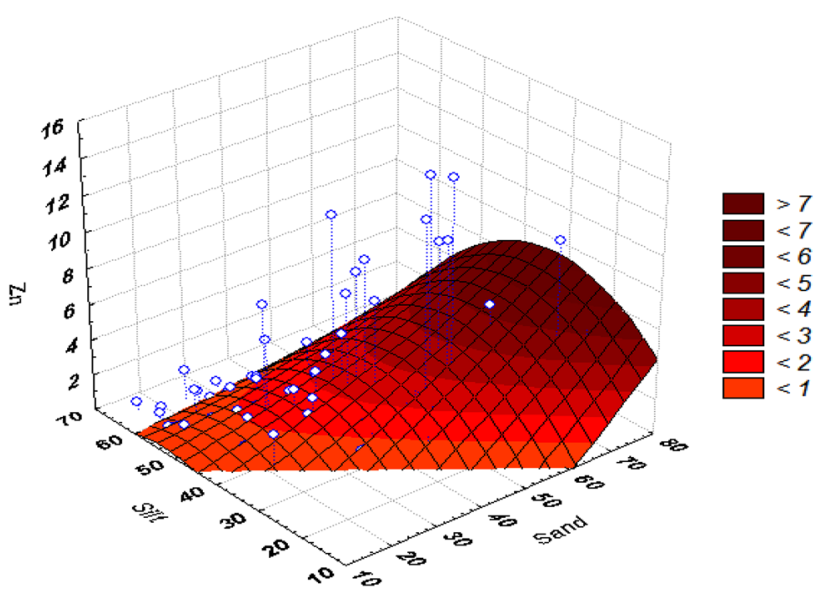

Fig. $103 \mathrm{D}$ surface plot of $\mathrm{Zn}(\mathrm{mg} / \mathrm{kg})$ against sand (\%) and silt (\%) 

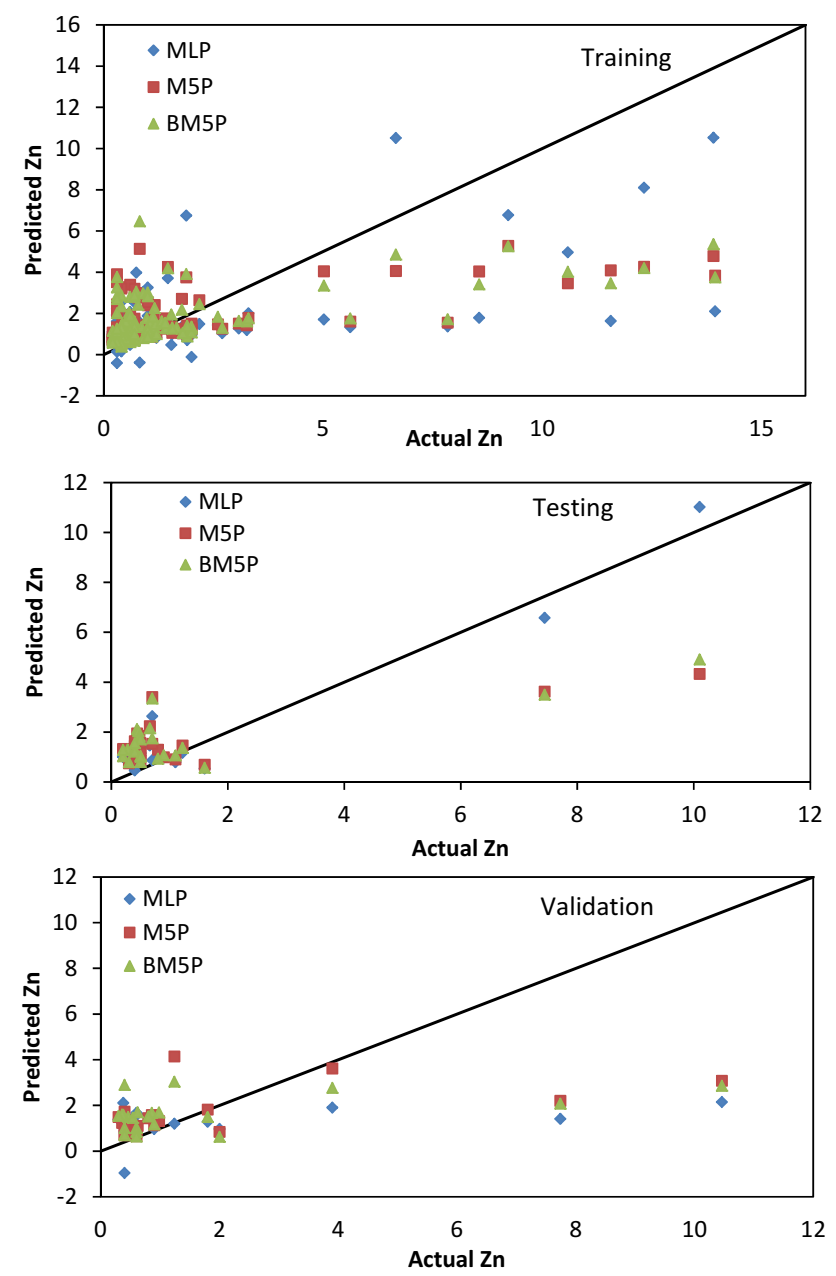

Fig. 11 Performance of MLP, M5P and BM5P for estimating Zn

\section{Discussion}

Generally, a quick and suitable method for estimating heavy metal contents in soil is illustrated in this investigation. Actually, experimentally investigation of heavy metal contents in soil is very expensive, hard, laborious and time-consuming, whereas computer-based methods are easier and less time-consuming. These methods provide a valid tool for estimating heavy metal contents in soil near mining and suburban regions, thus facilitating the management and assignment of human settlements and other natural resources. Previous studies have reported that statistical methods and artificial neural networks can be successfully applied for estimating various other heavy metal contents in soils in various regions [34-37]. In this study, four popular and dominant soft computing techniques were used for the estimation of heavy metals in soil. However, only four heavy metals were investigated in the present work. The influences of other heavy metals on the prediction accuracy were not taken into consideration.
From the results, it was observed that MLP-based models worked better than M5P- and BM5P-based models for the prediction of both Fe and Mn. Figure 4 suggests that estimation values of Cu using BM5P are close to line of perfect agreement than the values of other modeling (independent variables: organic carbon (OC), sand and silt). Figure 11 indicates that M5P models work superior than other approaches for the estimation of $\mathrm{Zn}$ with better standard statistical values (CC, RMSE, $d$, NSE, MAE). MLP model predicts some negative values in estimation of $\mathrm{Zn}$ metal. Overall performance of discussed approaches is satisfactory for the estimation of heavy metals in soil.

\section{Conclusions}

The prediction of soil pollution examines a significant field of study with regard to the overall concern of environmental protection issues. Determination of models that can accurately estimate the heavy metals in soils is an important need of agricultural researches, which could eliminate the weaknesses in the measurement of heavy metals in soils. In this study, using MLP, M5P and BM5P models, heavy metals ( $\mathrm{Zn}, \mathrm{Cu}, \mathrm{Mn}$ and Fe) were estimated and modeled for arid region of Iran. In this regard, different models have been developed for different metals using the above-discussed machine learning techniques. Finally, the accuracy of each model was investigated in terms of performance evaluation parameters. The experimental data collected from field samples were used in this study. The comparison of the performance of these models in predicting the heavy metals in soils showed that M5P model predicts the $\mathrm{Zn}$ content in soil and that BM5P model predicts the $\mathrm{Cu}$ content in soil with a much higher accuracy and less error than the other models. Outcomes of performance assessment parameters suggested that MLP model performed better than other models for predicting the $\mathrm{Mn}$ and Fe contents in soils. MLP Mn model included the combination of $\mathrm{pH}$, organic carbon (OC), clay, Ava. $\mathrm{P}$ and MLP Fe model included the combination of $\mathrm{pH}$, sand, silt and Ava. $P$ in this study.

\section{Compliance with ethical standards}

Conflict of interest Authors declared that there is no conflict of interest.

\section{References}

1. Dogra N, Sharma M, Sharma A, Keshavarzi A, Minakshi, Bhardwaj R, Thukral AK, Kumar V (2019) Pollution assessment and spatial 
distribution of roadside agricultural soils: a case study from India. Int J Environ Health Res 18:1-4

2. Keshavarzi A, Kumar V (2019) Spatial distribution and potential ecological risk assessment of heavy metals in agricultural soils of Northeastern, Iran. Geol Ecol Landsc. https://doi. org/10.1080/24749508.2019.1587588

3. Kumar V, Sharma A, Kaur P, Kumar R, Keshavarzi A, Bhardwaj $R$, Thukral AK (2019) Assessment of soil properties from catchment areas of Ravi and Beas rivers: a review. Geol Ecol Landsc 3(2):149-157

4. Keshavarzi A, Kumar V (2018) Ecological risk assessment and source apportionment of heavy metal contamination in agricultural soils of Northeastern Iran. Int J Environ Health Res 11:1-7

5. Kumar V, Sharma A, Bhardwaj R, Thukral AK (2016) Assessment of soil enzyme activities based on soil samples from the Beas river bed, India using multivariate techniques. Malay J Soil Sci 20:135-145

6. He ZL, Yang XE, Stoffella PJ (2005) Trace elements in agroecosystems and impacts on the environment. J Trace Elem Med Biol 19(2-3):125-140

7. Sun Y, Zhou Q, Xie X, Liu R (2010) Spatial, sources and risk assessment of heavy metal contamination of urban soils in typical regions of Shenyang, China. J Hazard Mater 174(1-3):455-462

8. Moor C, Lymberopoulou T, Dietrich VJ (2001) Determination of heavy metals in soils, sediments and geological materials by ICP-AES and ICP-MS. Microchim Acta 136(3-4):123-128

9. Kumar V, Sharma A, Kaur P, Sidhu GP, Bali AS, Bhardwaj R, Thukral AK, Cerda A (2019) Pollution assessment of heavy metals in soils of India and ecological risk assessment: a state-of-the-art. Chemosphere. https://doi.org/10.1016/j.chemosphere.2018.10.066

10. Zhang $X Y$, Lin FF, Wong MT, Feng XL, Wang K (2009) Identification of soil heavy metal sources from anthropogenic activities and pollution assessment of Fuyang County, China. Environ Monit Assess 154(1-4):439-449

11. Lin YP, Cheng BY, Shyu GS, Chang TK (2010) Combining a finite mixture distribution model with indicator kriging to delineate and map the spatial patterns of soil heavy metal pollution in Chunghua County, central Taiwan. Environ Pollut 158(1):235-244

12. Sidhu GP, Singh HP, Batish DR, Kohli RK (2017) Tolerance and hyperaccumulation of cadmium by a wild, unpalatable herb Coronopus didymus (L.) Sm. (Brassicaceae). Ecotoxicol Environ Saf 135:209-215

13. Sidhu GP, Bali AS, Singh HP, Batish DR, Kohli RK (2018) Phytoremediation of lead by a wild, non-edible $\mathrm{Pb}$ accumulator Coronopus didymus (L.) Brassicaceae. Int J Phytoremed 20(5):483-489

14. Sidhu GP, Bali AS, Singh HP, Batish DR, Kohli RK (2018) Ethylenediamine disuccinic acid enhanced phytoextraction of nickel from contaminated soils using Coronopus didymus (L.) Sm. Chemosphere 205:234-243

15. Khan S, Cao Q, Zheng YM, Huang YZ, Zhu YG (2008) Health risks of heavy metals in contaminated soils and food crops irrigated with wastewater in Beijing, China. Environ Pollut 152(3):686-692

16. Hu Y, Cheng H (2013) Application of stochastic models in identification and apportionment of heavy metal pollution sources in the surface soils of a large-scale region. Environ Sci Technol 47(8):3752-3760

17. Zovko M, Romic M (2011) Soil contamination by trace metals: geochemical behaviour as an element of risk assessment. In: Earth and environmental sciences. IntechOpen, pp 437-456

18. Wang Q, Xie Z, Li F (2015) Using ensemble models to identify and apportion heavy metal pollution sources in agricultural soils on a local scale. Environ Pollut 206:227-235

19. McBratney AB, Santos MM, Minasny B (2003) On digital soil mapping. Geoderma 117(1-2):3-52
20. Arun PV, Katiyar SK (2013) An evolutionary computing frame work toward object extraction from satellite images. Egypt J Remote Sens Space Sci 16(2):163-169

21. Scull P, Franklin J, Chadwick OA (2005) The application of classification tree analysis to soil type prediction in a desert landscape. Ecol Model 181(1):1-5

22. Thomas GW (1996) Soil pH and soil acidity. In: Page AL (ed) Methods of soil analysis: part 2. Agronomy handbook 9. American Society of Agronomy and Soil Science Society of America, Madison, Wl, pp 475-490

23. Gee GW, Bauder JW (1986) Particle size analysis. In: Klute A (ed) Methods of soil analysis: part 1. Agronomy handbook 9. American Society of Agronomy and Soil Science Society of America, Madison, WI, pp 383-411

24. Walkley A, Black IA (1934) An examination of the Degtjareff method for determining soil organic matter and a proposed modification of the chromic acid titration method. Soil Sci 37:29-38

25. Kumar V, Sharma A, Minakshi Bhardwaj R, Thukral AK (2018) Temporal distribution, source apportionment, and pollution assessment of metals in the sediments of Beas river, India. Hum Ecol Risk Assess 24(8):2162-2181

26. Xiao R, Bai J, Huang L, Zhang H, Cui B, Liu X (2013) Distribution and pollution, toxicity and risk assessment of heavy metals in sediments from urban and rural rivers of the Pearl River delta in southern China. Ecotoxicology 22(10):1564-1575

27. McCulloch WS, Pitts W (1943) A logical calculus of the ideas immanent in nervous activity. Bull Math Biophys 5(4):115-133

28. Schalkoff RJ (1997) Artificial neural networks, vol 1. McGraw-Hill, New York

29. Firat M, Gungor M (2009) Generalized regression neural networks and feed forward neural networks for prediction of scour depth around bridge piers. Adv Eng Softw 40(8):731-737

30. Ghorbani MA, Zadeh HA, Isazadeh M, Terzi O (2016) A comparative study of artificial neural network (MLP, RBF) and support vector machine models for river flow prediction. Environ Earth Sci 75(6):476

31. Quinlan JR (1992) Learning with continuous classes. In: 5th Australian joint conference on artificial intelligence, vol 92, pp 343-348

32. Breiman L (1996) Bagging predictors. Mach Learn 24(2):123-140

33. Breiman $L$ (1999) Using adaptive bagging to debias regressions. Technical report 547, Statistics Department, UCB

34. Kemper T, Sommer S (2002) Estimate of heavy metal contamination in soils after a mining accident using reflectance spectroscopy. Environ Sci Technol 36(12):2742-2747

35. Alizamir M, Sobhanardakani S, Taghavi L (2017) Modeling of groundwater resources heavy metals concentration using soft computing methods: application of different types of artificial neural networks. J Chem Health Risks 7(3):68-77

36. Alizamir M, Sobhanardakani S (2017) A comparison of performance of artificial neural networks for prediction of heavy metals concentration in groundwater resources of toyserkan plain. Avicenna J Environ Health Eng 4(1):11792

37. Alizamir M, Sobhanardakani S (2017) Predicting arsenic and heavy metals contamination in groundwater resources of Ghahavand plain based on an artificial neural network optimized by imperialist competitive algorithm. Environ Health Eng Manag J $4: 225-231$

Publisher's Note Springer Nature remains neutral with regard to jurisdictional claims in published maps and institutional affiliations. 